\title{
Psychometric evaluation of the German version of the Opening Minds Stigma Scale for Health Care Providers (OMS-HC)
}

\author{
Gianfranco Zuaboni ${ }^{*}$, Timon Elmer ${ }^{2}$, Franziska Rabenschlag ${ }^{3}$, Kolja Heumann $^{4}$, Susanne Jaeger ${ }^{5}$, Bernd Kozel $^{6}$, \\ Candelaria I. Mahlke , Anastasia Theodoridou ${ }^{8}$, Matthias Jaeger ${ }^{8,9}$ and Nicolas Rüsch ${ }^{10}$
}

\begin{abstract}
Background: Healthcare professionals can be a source of stigma and discrimination for people with mental illness, and anti-stigma programs are needed for this target group. However, there is no validated German language scale to assess attitudes of healthcare professionals towards people with mental illness. This study had the aim to validate the German language version of the Opening Minds Stigma Scale for Health Care Providers (OMS-HC), a self-report measure of stigmatizing attitudes.
\end{abstract}

Methods: Staff $(n=392)$ on general psychiatric inpatient wards (excluding child, forensic and geriatric psychiatry) at five psychiatric hospitals in Switzerland $(n=3)$ and Germany $(n=2)$ participated in the study. The internal consistency of the OMS-HC was examined as well as its factor structure using exploratory and confirmatory factor analyses. To assess the scale's concurrent validity, we used the Social Distance Scale.

Results: Internal consistency for the OMS-HC total score was good $(a=0.74)$, acceptable for the subscales Attitudes $(a=0.62)$ and Social Distance $(a=0.69)$, and poor for the Disclosure subscale $(a=0.55)$. The original three-factor structure fit our data well. The OMS-HC total score and the Social Distance subscale score were significantly correlated with the Social Distance Scale, supporting concurrent validity.

Conclusion: The German version of the OMS-HC demonstrated satisfactory psychometric properties and can be recommended for future research and intervention evaluation.

Keywords: Attitudes, Stigma, Social distance, Therapeutic relationship, Psychometrics, Recovery, Mental illness

\section{Background}

Stigmatization by healthcare professionals (HCP) is widespread and has serious consequences, including poorer physical and mental healthcare for people with mental health problems (PWM) [1-3]. An explanation may be the perceived difference between HCP and PWM, i.e. that "they" (PWM) are completely different

\footnotetext{
*Correspondence: g.zuaboni@sanatorium-kilchberg.ch

${ }^{1}$ Sanatorium Kilchberg AG, Psychiatric and Psychotherapy Hospital, Alte Landstrasse 70, 8802 Kilchberg, Switzerland

Full list of author information is available at the end of the article
}

from "us" (HCP) $[4,5]$. Stigma experienced or anticipated by PWM can impair the therapeutic relationship with HCPs, which in turn has a negative impact on the recovery process [6-8]. Many barriers to use healthcare services are related to stigma [9]. As a result, PWM are not taken seriously and do not receive the treatment they need, with negative health consequences and lower life expectancy than the general population $[10,11]$.

From a stigma perspective, mental healthcare professionals can be sources of stigma if they endorse stigmatizing attitudes. However, they can also be agents for change and allies of people with mental illness. That may 
especially apply to situations in which they disclose their experience of own mental health problems to colleagues, patients or others [12]. There is no evidence that attitudes towards people with mental illness are less negative among German-speaking healthcare professionals compared to other countries [13]. This highlights the need for measures to rigorously evaluate anti-stigma interventions for this key target group. However, we are not aware of a validated German language scale in this domain.

The Opening Minds Stigma Scale for Health Care Providers (OMS-HC) was developed to gauge the attitudes of HCPs towards PWM [14]. Initially a 20-item version of the OMS-HC was administered to $787 \mathrm{HCPs}$ across Canada and a factor analysis yielded inconsistent findings. Another factor analysis was conducted in a larger and more representative sample with the 20 -item version [15], resulting in a 3-factor solution: (1) attitudes, (2) disclosure and help-seeking, and (3) social distance as well and resulted in a briefer 15 -item version. The overall internal consistency was $\alpha=0.79$ for the 15 -item scale and $\alpha=0.67$ (disclosure) or $\alpha=0.68$ (attitudes, social distance) for the subscales.

In this study, we present the results of the psychometric examination of a German translation of the 15-item OMS-HC in terms of its internal consistency, factor structure and concurrent validity.

\section{Methods}

\section{Translation procedure}

The translation procedure followed recognized guidelines [16]. The translation of the original OMS-HC (Additional file 1) into German was conducted by an experienced mental health nurse. The German version was then back-translated into English by a bilingual peer worker. Together with a bilingual psychiatrist, the two translators compared and discussed the two English versions and the German translation. The revised German version was then carefully discussed with a group of mental health nurses, psychologists and psychiatrists $(n=9)$. Based on the group discussion, minor adjustments were made to improve the clarity of the German version, resulting in the final version evaluated in this study.

\section{Design and participants}

This study was part of a larger cross-sectional study, which was conducted among staff on general psychiatric inpatient wards (excluding child, forensic and geriatric psychiatry; $n=1629$ ) at five psychiatric hospitals in Switzerland $(n=3)$ and Germany $(n=2)[17,18]$. All HCP staff in all five hospitals that worked directly with patients were invited to participate in the study. Among participants who volunteered for this study, an online survey was conducted in each hospital, the study was approved either by the board of directors or the respective ethics committee. Participation was voluntary.

Of the eligible HCPs $(n=1629), 428(26 \%)$ participated and 397 completed the OMS-HC questionnaire. Due to missing data or implausible response patterns, five participants were excluded from the analysis and 392 remained. About one third were male, and the most common profession was mental health nursing, followed by psychiatrists and psychologists (Table 1).

\section{Measures \\ Opening Minds Stigma Scale for Health Care Providers}

Participants completed online the German version of the Opening Minds Stigma Scale for Health Care Providers (OMS-HC). It is a self-report questionnaire with 15 items (e.g. "There is little I can do to help people with mental illness"), with a 5 -point Likert scale (1/strongly disagree, 2 /disagree, $3 /$ neither agree nor disagree, 4 /agree, $5 /$ strongly agree). Items $2,6,7$ and 8 are reverse-coded. The scale yields a mean score from 1 to 5 , with higher scores indicating more stigmatizing attitudes. The English items can be found in Table 2 and in the Additional file 1, the German version is provided in Additional file 2.

\section{Social distance scale}

The desire for social distance from people with mental illness was assessed by the Social Distance Scale (SDS), based on Bogardus' work and frequently used by Bruce Link and his colleagues [19]. The scale includes seven items (e.g. "How would you feel having someone with a severe mental illness as a neighbor?"). Respondents rated each question from 0 (definitely willing) to 3 (definitely unwilling). The overall SDS score represents the mean of

Table 1 Sample characteristics

\begin{tabular}{lcr}
\hline Gender & $\mathbf{n}$ & $\%$ \\
\hline Female & 244 & 62.2 \\
Male & 148 & 37.8 \\
Age & & \\
18-25 years & 35 & 8.9 \\
26-35 years & 130 & 33.2 \\
36-45 years & 95 & 24.2 \\
46-55 years & 97 & 24.7 \\
>55 years & 35 & 8.9 \\
Profession & & 66.3 \\
Mental health nurse & 260 & 12.5 \\
Physician & 49 & 5.9 \\
Psychologist & 23 & 4.1 \\
Social worker & 16 & 11.2 \\
Other (occupational therapist, art & 44 & \\
$\quad$ therapist) & & \\
\hline
\end{tabular}


Table 2 Factor analysis with varimax rotation $(n=392)$; factor loadings $>0.40$ in bold

\begin{tabular}{|c|c|c|c|c|c|}
\hline & \multicolumn{3}{|c|}{ Factors } & \multirow{2}{*}{$\begin{array}{l}\text { Item-total } \\
\text { correlation }\end{array}$} & \multirow[t]{2}{*}{ Alpha if deleted } \\
\hline & 1 & 2 & 3 & & \\
\hline \multicolumn{6}{|l|}{ Factor 1: Attitudes of healthcare providers towards people with mental illness } \\
\hline $\begin{array}{l}\text { 1. I am more comfortable helping a person who has a physical illness than I am helping a person } \\
\text { who has a mental illness }\end{array}$ & 0.45 & 0.16 & 0.19 & 0.49 & 0.72 \\
\hline $\begin{array}{l}\text { 9. Despite my professional beliefs, I have negative reactions towards people who have mental } \\
\text { illness }\end{array}$ & 0.48 & 0.23 & 0.10 & 0.48 & 0.72 \\
\hline 10. There is little I can do to help people with mental illness & 0.44 & 0.07 & 0.05 & 0.37 & 0.73 \\
\hline 11. More than half of people with mental illness don't try hard enough to get better & 0.33 & 0.19 & 0.22 & 0.48 & 0.72 \\
\hline 13. Healthcare providers do not need to be advocates for people with mental illness & 0.22 & -0.04 & 0.25 & 0.39 & 0.74 \\
\hline 15. I struggle to feel compassion for a person with a mental illness & 0.45 & 0.06 & 0.33 & 0.51 & 0.72 \\
\hline \multicolumn{6}{|l|}{ Factor 2: Disclosure/help-seeking } \\
\hline 3. If I were under treatment for a mental illness, I would not disclose this to any of my colleagues & 0.03 & 0.40 & 0.03 & 0.35 & 0.72 \\
\hline 4. I would see myself as weak if I had a mental illness and could not fix it myself & 0.21 & 0.56 & 0.08 & 0.49 & 0.72 \\
\hline 5. I would be reluctant to seek help if I had a mental illness & 0.18 & 0.50 & 0.03 & 0.47 & 0.73 \\
\hline 8. If I had a mental illness, I would tell my friends ${ }^{\mathrm{a}}$ & 0.00 & 0.28 & 0.35 & 0.44 & 0.73 \\
\hline \multicolumn{6}{|l|}{ Factor 3: Social distance } \\
\hline $\begin{array}{l}\text { 2. If a colleague with whom I work told me they had a managed mental illness, I would be just as } \\
\text { willing to work with him/her }\end{array}$ & 0.15 & 0.00 & 0.52 & 0.46 & 0.72 \\
\hline $\begin{array}{l}\text { 6. Employers should hire a person with a managed mental illness if he/she is the best person for } \\
\text { the job }^{\mathrm{a}}\end{array}$ & 0.05 & 0.06 & 0.68 & 0.51 & 0.72 \\
\hline 7. I would still go to a physician if I knew that the physician had been treated for a mental illness ${ }^{a}$ & 0.25 & 0.01 & 0.61 & 0.56 & 0.71 \\
\hline $\begin{array}{l}\text { 12. I would not want a person with a mental illness, even if it were appropriately managed, to } \\
\text { work with children }\end{array}$ & 0.22 & 0.14 & 0.47 & 0.57 & 0.71 \\
\hline 14. I would not mind if a person with a mental illness lived next door to me $\mathrm{a}^{\mathrm{a}}$ & 0.16 & 0.22 & 0.38 & 0.51 & 0.72 \\
\hline
\end{tabular}

Bartlett's test of sphericity $\left(x^{2}=857.25, p<2.2 \mathrm{e}-16\right)$ and the Kaiser-Meyer-Olkin value was 0.811 ; alpha $=0.74$ (0.62 for factor $1,0.55$ for factor 2 , and 0.69 for factor 3$)$

a Reverse-scored item

all seven items from 0 to 3, with higher scores indicating stronger social distance (Cronbach's alpha in our study was 0.75$)$.

\section{Ethics}

The cantonal ethics committee of Zurich confirmed to us in writing that the study does not fall within its area. The study was approved by the local ethics committee (Ethics Committee of the University of Ulm) and the internal ethics officer (University Medical Center Hamburg-Eppendorf). Furthermore, in all hospitals, the board of directors and the other relevant clinics' internal departments (personal departments, departments of quality management and data protection commissioners) agreed with the study protocol. Participation in the study was voluntary and anonymous. The informed consent was obtained from all participants. All methods of the study were carried out in accordance with relevant guidelines.

\section{Statistical analysis}

The internal consistency of the OMS-HC was assessed using Cronbach's alpha for the total score and each subscale. To determine the scale's factor structure, we took a two-step approach. First, we explored the factor structure and factor loadings of each item in our data using exploratory factor analysis (EFA). Differences in factor loadings could result from cultural and contextual differences in the endorsement of stigma by mental health care workers. Therefore we also conducted a confirmatory factor analysis (CFA) to compare our data to the initial factor structure reported by Modgil et al. [15]. The fit indices of the CFA were evaluated with respect to existing fit criteria for CFAs [20], with good model fit indicated by $\mathrm{CFI} \geq 0.95$, SRMR $\leq 0.08$, RMSEA $\leq 0.06$ ). Concurrent validity was examined by Pearson correlations between the OMS-HC and the SDS scale. The R Software Packages psych [21] and lavaan [22] with the WLSMV estimator were used to conduct the EFA and CFA, respectively. We used Hmisc [23] for the calculation of the correlations and psych [21] was used to assess reliability. 


\section{Results}

\section{Descriptives}

On average, participants scored an OMS-HC total mean of $1.94(\mathrm{SD}=0.41)$. In the three subscales the following means were obtained: $M=1.71$ for attitudes $(S D=0.45)$, $M=1.91$ for social distance $(S D=0.58)$, and $M=2.32$ for disclosure and help seeking $(\mathrm{SD}=0.64)$. With regards to the Social Distance Scale (SDS), participants on average obtained a value of $2.21(\mathrm{SD}=0.79)$.

\section{Internal consistency and intercorrelations}

The Cronbach's alpha for the German version of the OMS-HC scale indicated good internal consistency $(\alpha=0.74)$, whereas internal consistency for the subscales Attitudes $(\alpha=0.62)$ and Social Distance $(\alpha=0.69)$ was acceptable and poor for the subscale Disclosure $(\alpha=0.55)$. The total score of the OMS-HC correlated strongly with the subscales (attitudes: $r=0.78$, disclosure: $r=0.68$, social distance: $r=0.78$ ) and the subscales were moderately intercorrelated (see Table 3 for details).

\section{Factor analyses}

An EFA was carried out to explore the factor structure and factor loadings in our data (Table 2). The EFA provided a three factors solution with eigenvalues of 3.49, 1.54 , and 1.21 .

Of the six items of factor 1 (attitudes), five had a factor loading of $0.33-0.48$ and one had only 0.22 . Of the four items of factor 2 (disclosure), three had a factor loading of $0.40-0.56$ and one had 0.28 . For factor 3 (social distance), the five items had values from 0.38 to 0.68 . Item 11 showed cross-loadings on all three factors (Table 2), item 13 on factors 1 and 3, item 8 on factors 2 and 3, and item 14 on all three factors.

In our CFA to examine the fit of our data to the original three-factor structure, there was a good model fit according to the criteria of $\mathrm{Hu}$ and Bentler [20] with $X^{2}(87)=149.29, p<0.001$, comparative fit index $(\mathrm{CFI})=0.92$, standardized root mean square residual $(\mathrm{SRMR})=0.05$; root mean square error of approximation $($ RMSEA $)=0.04$; RMSEA 90\% confidence interval $(C I)=[0.03-0.05]$. A significant $X^{2}$ test does not necessarily suggest poor model fit as it is considered highly sensitive in large samples [24]. Figure 1 shows factor loadings of this CFA. There are low factor loadings for some items (e.g., Item 3). These low factor loadings likely show the unique contribution of the respective item to the theoretical construct. They do not significantly worsen the model fit as they do not load better on other factors (see EFA and Table 2; e.g., Item 3 loads with 0.40 on the disclosure factor, but only with 0.03 and 0.03 on the other two).

\section{Concurrent validity}

Pearson correlations were calculated between the OMS$\mathrm{HC}$ total score, the three subscale scores and the SDS total score (Table 3). All four correlations were significantly positive, especially between SDS and the OMS-HC total and social distance subscale scores.

\section{Discussion}

Our results provide evidence for good psychometric properties of the German version of the OMS-HC scale. The internal consistency of the OMS-HC was good for the total score and satisfactory for two subscales. The fact that the four-item Disclosure subscale showed poor internal consistency might be related to its small item number, which generally is linked to lower alpha values [26]. The internal consistency in our study was similar to the original study [15] regarding the total score, but slightly poorer with respect to the subscale scores.

The factor loadings of items in our exploratory factor analysis suggested that two items (8 and 13) loaded more on the Social Distance factor 3 than on factor 1 or 2, respectively, to which they belonged in the original factor solution. A possible explanation is that item 8 is reverse-scored which may have led to some incorrect answers [27]. Another explanation are contextual, cultural and healthcare system differences between Canada and European countries like Germany and Switzerland regarding the concept of friendship (item 8) [28]. Regarding item 13 ("advocacy for people with mental health problems"), the concept of advocacy may be more intuitive in Canada than it is in German speaking countries and advocacy for people with mental illness could be shaped by conflictual experiences of MHP

Table 3 Pearson correlations of the OMS-HC subscales and the Social Distance Scale (SDS)

\begin{tabular}{llll}
\hline & OMS total score & OMS attitude & OMS disclosure \\
\hline OMS attitude & $0.78^{* * *}$ & & \\
OMS disclosure & $0.68^{* * *}$ & $0.30^{* * *}$ & $0.45^{* * *}$ \\
OMS distance & $0.78^{* * *}$ & $0.25^{* * *}$ & $0.19^{* * *}$ \\
SDS & $0.46^{* * *}$ & $0.58^{* * *}$ \\
\hline
\end{tabular}

${ }^{* *} p<0.01 ;{ }^{* *} p<0.001$ 


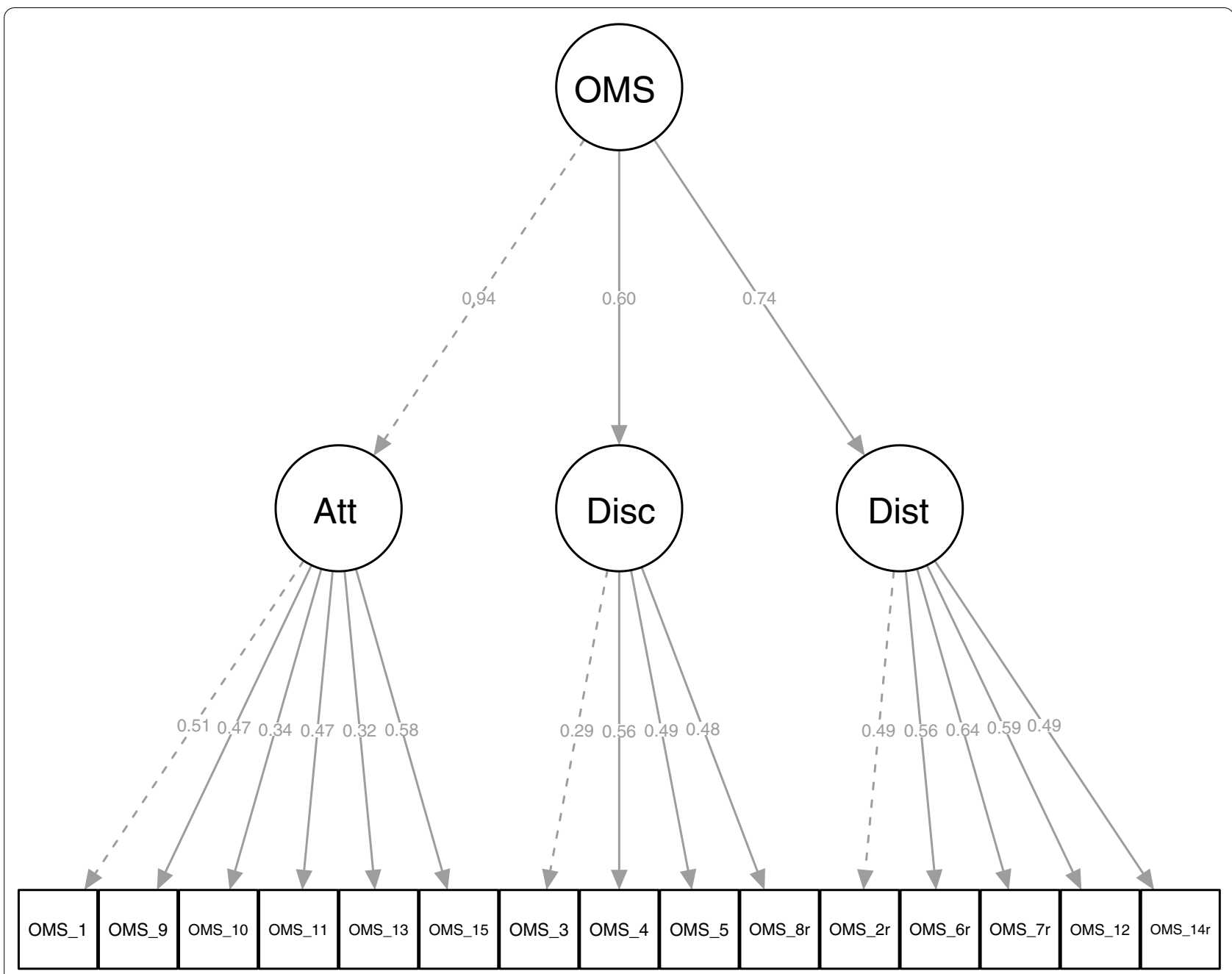

Fig. 1 Factor loadings of the confirmatory factor analysis with three factors attitude, disclosure, and social distance. The dashed lines indicate which item was used for the scaling by fixing factor loadings. The figure was created using the semPlot R-package [25]

[29-31]. The working environment of participants in acute-care psychiatric settings can be characterized by coercion and involuntary admission, which causes emotional reactions in the patients, such as shame and self-stigma [32] and can impair the therapeutic working relationship [33]. Based on these assumptions and given that the two items may cover a unique aspect of the construct, we would recommend to leave them in the scale. However, it remains to be examined in further research whether a more heterogenous composition of the population (HCPs outside of acute-care psychiatric settings) affects the psychometric properties of these two items.

The confirmatory factor analysis showed good model fit with respect to the original version. This is in line with a recent OMS-HC validation in Chile and partly consistent with a Hungarian study that ran a series of factor analyses, resulting in a final two-factor solution [34, 35].

\section{Strengths and limitations}

This study provides the first psychometric evaluation of the German version of the OMS-HC. Participants were recruited in two different countries, representing data from two different health-care systems. A key limitation of this study is the non-representative sample of participants, mainly recruited from the acute-care inpatient psychiatric sector as a convenience sample that is not representative for all healthcare professionals. Various studies have shown differences in attitudes between professionals in outpatient versus inpatient settings [36-38] and psychiatric versus non-psychiatric healthcare systems [2]. Finally, our cross-sectional data did not allow us to assess retest reliability or sensitivity to change during an intervention. 


\section{Conclusion}

On the basis of our findings, the OMS-HC can be recommended to assess attitudes of mental health professionals towards people with mental illness and can be usefully applied to effectively develop and evaluate anti-stigma workshops and campaigns in healthcare settings. However, it is advisable to conduct further psychometric tests on a more diverse sample with an emphasis on testing sensitivity to change.

\section{Supplementary Information}

The online version contains supplementary material available at https://doi. org/10.1186/s40359-021-00592-9.

Additional file 1. The original English version of the Opening Minds Stigma Scale for Health Care Providers (OMS-HC-15)

Additional file 2. The German translation of the Opening Minds Stigma Scale for Health Care Providers (OMS-HC)

\section{Acknowledgements}

We would like to thank Dominik Schori of the Directorate of Nursing, Therapies and Social Work, University Hospital of Psychiatry Zurich, for contributing to the conception and design of the survey and collection of the data and the mental health staff who participated in the study and completed the questionnaires.

\section{Authors' contributions}

GZ, TE, FR, BK and MJ made substantial contributions to the conception and design. GZ and NR contributed to the scale translation. GZ, FR, BK, SJ, KH, CM AT and MJ made substantial contributions to data acquisition. GZ, TE and NR made substantial contributions to the analysis and interpretation of the data. GZ, TE and NR were involved in drafting the manuscript. All authors were involved in the revision of the manuscript. All authors gave final approval of the version to be published.

\section{Funding}

This research was supported by the Swiss National Science Foundation (Grant No.: P2EZP1_188022). Additionally, the study has received funding from an internal research fund belonging to the Psychiatric Hospitals of the University of Basel, Switzerland. The sponsors had no further involvement in the study or publication.

\section{Availability of data and materials}

The datasets used and/or analyzed during the current study are available from the corresponding author on reasonable request.

\section{Declarations}

\section{Ethics approval and consent to participate}

The cantonal ethics committee of Zurich confirmed to us in writing that the study does not fall within its area. The study was approved by the local ethics committee (Ethics Committee of the University of UIm) and the internal ethics officer (University Medical Center Hamburg-Eppendorf). Furthermore, in all hospitals, the board of directors and the other relevant clinics' internal departments (personal departments, departments of quality management and data protection commissioners) agreed with the study protocol. Participation in the study was voluntary and anonymous. The informed consent was obtained from all subjects, or if they were under 18 years, from a parent or a legal guardian. All methods of the study were carried out in accordance with relevant guidelines.

\section{Consent for publication}

Not applicable.

\section{Competing interests}

The authors declare that they have no competing interests.

\section{Author details}

${ }^{1}$ Sanatorium Kilchberg AG, Psychiatric and Psychotherapy Hospital, Alte Landstrasse 70, 8802 Kilchberg, Switzerland. 'University of Groningen, Groningen, The Netherlands. ${ }^{3}$ Psychiatric University Clinics Basel, Basel, Switzerland. ${ }^{4}$ Department of Psychiatry and Psychotherapy, Medical University Brandenburg, Neuruppin, Germany. ${ }^{5}$ Department of Psychiatry and Psychotherapy I, Ulm University, ZfP Südwürttemberg, Ravensburg, Germany. ${ }^{6}$ University Psychiatric Services Bern, Bern, Switzerland. 'D Department of Psychiatry and Psychotherapy, University Medical Centre Hamburg-Eppendorf (UKE), Hamburg, Germany. ${ }^{8}$ Department of Psychiatry, Psychotherapy and Psychosomatics, University Hospital of Psychiatry Zurich, Zurich, Switzerland. ${ }^{9}$ Psychiatrie Baselland, Liestal, Switzerland. ${ }^{10}$ Department of Psychiatry and Psychotherapy II, Ulm University and BKH Günzburg, Ulm/Günzburg, Germany.

Received: 22 December 2020 Accepted: 12 April 2021

Published online: 21 May 2021

\section{References}

1. Farrelly S, Jeffery D, Rüsch N, Williams $P$, Thornicroft G, Clement S. The link between mental health-related discrimination and suicidality: service user perspectives. Psychol Med. 2015;45(10):2013-22.

2. Perry A, Lawrence V, Henderson C. Stigmatisation of those with mental health conditions in the acute general hospital setting. A qualitative framework synthesis. Soc Sci Med. 2020;255:112974.

3. Henderson C, Noblett J, Parke H, Clement S, Caffrey A, Gale-Grant $\mathrm{O}$, Schulze B, Druss B, Thornicroft G. Mental health-related stigma in health care and mental health-care settings. The Lancet Psychiatry. 2014;1(6):467-82.

4. Link BG, Phelan JC. Conceptualizing stigma. Ann Rev Sociol. 2001;27(1):363-85

5. von Peter S, Schulz G. 'I-as-We'-Powerful boundaries within the field of mental health coproduction. Int J Ment Health Nurs. 2018;27:1292-300.

6. Harris B, Panozzo G. Barriers to recovery-focused care within therapeutic relationships in nursing: Attitudes and perceptions. Int J Ment Health Nurs. 2019;28:1220-7.

7. Xu Z, Lay B, Oexle N, DrackT, Bleiker M, Lengler S, Blank C, Müller M, Mayer $B$, Rössler W, et al. Involuntary psychiatric hospitalisation, stigma stress and recovery: a 2-year study. Epidemiol Psychiatr Sci. 2019;28(4):458-65.

8. Oexle N, Müller M, Kawohl W, Xu Z, Viering S, Wyss C, Vetter S, Rüsch N. Self-stigma as a barrier to recovery: a longitudinal study. Eur Arch Psychiatry Clin Neurosci. 2018:268(2):209-12.

9. Clement S, Schauman O, Graham T, Maggioni F, Evans-Lacko S, Bezborodovs N, Morgan C, Rüsch N, Brown JS, Thornicroft G. What is the impact of mental health-related stigma on help-seeking? A systematic review of quantitative and qualitative studies. Psychol Med. 2015;45(1):11-27.

10. Wahlbeck K, Westman J, Nordentoft M, Gissler M, Laursen TM. Outcomes of Nordic mental health systems: life expectancy of patients with mental disorders. Br J Psychiatry. 2011;199(6):453-8.

11. Lawrence D, Hancock KJ, Kisely S. The gap in life expectancy from preventable physical illness in psychiatric patients in Western Australia: retrospective analysis of population based registers. BMJ. 2013;346:f2539.

12. Grice T, Alcock K, Scior K. Mental health disclosure amongst clinical psychologists in training: Perfectionism and pragmatism. Clin Psychol Psychother. 2018;25(5):721-9.

13. Lauber C, Nordt C, Braunschweig C, Rössler W. Do mental health professionals stigmatize their patients? Acta Psychiatr Scand Suppl. 2006;429:51-9.

14. Kassam A, Papish A, Modgill G, Patten S. The development and psychometric properties of a new scale to measure mental illness related stigma by health care providers: the opening minds scale for health care providers (OMS-HC). BMC Psychiatry. 2012;12:62.

15. Modgill G, Patten SB, Knaak S, Kassam A, Szeto AC. Opening minds stigma scale for health care providers (OMS-HC): examination of psychometric properties and responsiveness. BMC Psychiatry. 2014;14:120. 
16. Beaton DE, Bombardier C, Guillemin F, Ferraz MB. Guidelines for the process of cross-cultural adaptation of self-report measures. Spine. 2000:25(24):3186-91.

17. Elmer T, Rabenschlag F, Schori D, Zuaboni G, Kozel B, Jaeger S, Mahlke C, Heumann K, Theodoridou A, Jaeger M. Informal coercion as a neglected form of communication in psychiatric settings in Germany and Switzerland. Psychiatry Res. 2018;262:400-6.

18. Schori D, Jaeger M, Elmer T, Jaeger S, Mahlke C, Heumann K, Theodoridou A, Zuaboni G, Kozel B, Rabenschlag F. Knowledge on types of treatment pressure. A cross-sectional study among mental health professionals. Arch Psychiatr Nurs. 2018;32:662-9.

19. Link BG, Cullen FT, Frank J, Wozniak JF. The social rejection of former mental patients: understanding why labels matter. Am J Sociol. 1987;92(6):1461-500.

20. Hu L, Bentler PM. Cutoff criteria for fit indexes in covariance structure analysis: Conventional criteria versus new alternatives. Struct Equ Model: A Multidiscip J. 1999;6(1):1-55.

21. Revelle W. Psych: Procedures for psychological, psychometric, and personality research. In: R package version 2.0.9 edn: Northwestern University, Evanston; 2020

22. Rosseel Y. lavaan: An R Package for structural equation modeling. 2012, 48(2):36.

23. Harrell Jr FE: M.C. Dupont R Package Hmisc R foundation for statistical computing. In. Vienna; 2014: https://cran.r-project.org/web/packages/ Hmisc/Hmisc.pdf

24. Brown TA. Confirmatory factor analysis for applied research. New York: Guilford Press; 2006

25. Epskamp S. semPlot: Unified visualizations of structural equation models. Struct Equ Modeling. 2015;22(3):474-83.

26. Ponterotto JG, Ruckdeschel DE. An Overview of coefficient alpha and a reliability matrix for estimating adequacy of internal consistency coefficients with psychological research measures. Percept Mot Skills. 2007;105(3):997-1014.

27. Schmitt N, Stuits DM. Factors defined by negatively keyed items: The result of careless respondents? Appl Psychol Meas. 1985:9(4):367-73.

28. Adams RG. Placing friendship in context. Cambridge: Cambridge University Press; 1998.
29. Chambers M, Kantaris X, Guise V, Valimaki M. Managing and caring for distressed and disturbed service users: the thoughts and feelings experienced by a sample of English mental health nurses. J Psychiatr Ment Health Nurs. 2015;22:289-97.

30. Wijnveld AM, Crowe M. Walking a fine line: managing the tensions associated with medication non-adherence in an acute inpatient psychiatric setting. J Clin Nurs. 2010;19(9-10):1378-86.

31. Abbasinia M, Ahmadi F, Kazemnejad A. Patient advocacy in nursing: A concept analysis. Nurs Ethics. 2020;27(1):141-51.

32. Rüsch N, Müller M, Lay B, Corrigan PW, Zahn R, Schönenberger T, Bleiker M, Lengler S, Blank C, Rössler W. Emotional reactions to involuntary psychiatric hospitalization and stigma-related stress among people with mental illness. Eur Arch Psychiatry Clin Neurosci. 2014;264(1):35-43.

33. Lawrence RE, Perez-Coste MM, Bailey JL, DeSilva RB, Dixon LB. Coercion and the inpatient treatment alliance. Psychiatr Serv. 2019;70(12):1110-5.

34. Ori D, Rozsa S, Szocsics P, Simon L, Purebl G, Gyorffy Z. Factor structure of the opening minds stigma scale for health care providers and psychometric properties of its Hungarian version. BMC Psychiatry. 2020;20(1):504

35. Sapag JC, Klabunde R, Villarroel L, Velasco PR, Alvarez C, Parra C, Bobbili SJ, Mascayano F, Bustamante I, Alvarado R, et al. Validation of the opening minds scale and patterns of stigma in Chilean primary health care. PLoS ONE. 2019;14(9):e0221825.

36. Tsai J, Salyers M, Lobb A. Recovery-oriented training and staff attitudes over time in two state hospitals. Psychiatr Q. 2010;81(4):335-47.

37. Gyamfi N, Bhullar N, Islam MS, Usher K. Knowledge and attitudes of mental health professionals and students regarding recovery: A systematic review. Int J Ment Health Nurs. 2020;29:322-47.

38. Giusti L, Ussorio D, Salza A, Malavolta M, Aggio A, Bianchini V, Casacchia $M$, Roncone R. Italian investigation on mental health workers' attitudes regarding personal recovery from mental illness. Community Ment Health J. 2019;55(4):680-5.

\section{Publisher's Note}

Springer Nature remains neutral with regard to jurisdictional claims in published maps and institutional affiliations.
Ready to submit your research? Choose BMC and benefit from:

- fast, convenient online submission

- thorough peer review by experienced researchers in your field

- rapid publication on acceptance

- support for research data, including large and complex data types

- gold Open Access which fosters wider collaboration and increased citations

- maximum visibility for your research: over $100 \mathrm{M}$ website views per year

At $\mathrm{BMC}$, research is always in progress.

Learn more biomedcentral.com/submissions 